Journal of Marine Systems

October 2016, Volume 162, Pages 112-125

http://dx.doi.org/10.1016/j.jmarsys.2016.04.003

http://archimer.ifremer.fr/doc/00324/43545/

(c) 2016 Elsevier B.V. All rights reserved.

\title{
Optimizing observational networks combining gliders, moored buoys and FerryBox in the Bay of Biscay and English Channel
}

\author{
Charria Guillaume ${ }^{1,{ }^{*}}$, Lamouroux Julien ${ }^{2}$, De Mey Pierre ${ }^{3}$
}

1 IFREMER, DYNECO/PHYSED, ZI de la pointe du diable, CS 10070, 292806 Plouzané, France

${ }^{2}$ NOVELTIS, 153 rue du Lac, 31670, Labège, France

${ }^{3}$ CNRS, LEGOS/UMR 5566, 18, av. Edouard Belin, 31401 Toulouse cedex 9, France

* Corresponding author : Guillaume Charria, Tel.: +33(0)298224330 - Fax: +33(0)298224864 ;

email address : guillaume.charria@ifremer.fr

\begin{abstract}
:
Designing optimal observation networks in coastal oceans remains one of the major challenges towards the implementation of future efficient Integrated Ocean Observing Systems to monitor the coastal environment. In the Bay of Biscay and the English Channel, the diversity of involved processes (e.g. tidally-driven circulation, plume dynamics) requires to adapt observing systems to the specific targeted environments. Also important is the requirement for those systems to sustain coastal applications.
\end{abstract}

Two observational network design experiments have been implemented for the spring season in two regions: the Loire River plume (northern part of the Bay of Biscay) and the Western English Channel. The method used to perform these experiments is based on the ArM (Array Modes) formalism using an ensemble-based approach without data assimilation.

The first experiment in the Loire River plume aims to explore different possible glider endurance lines combined with a fixed mooring to monitor temperature and salinity. Main results show an expected improvement when combining glider and mooring observations. The experiment also highlights that the chosen transect (along-shore and North-South, cross-shore) does not significantly impact the efficiency of the network. Nevertheless, the classification from the method results in slightly better performances for along-shore and North-South sections.

In the Western English Channel, a tidally-driven circulation system, added value of using a glider below FerryBox temperature and salinity measurements has been assessed. FerryBox systems are characterised by a high frequency sampling rate crossing the region 2 to 3 times a day. This efficient sampling, as well as the specific vertical hydrological structure (which is homogeneous in many subregions of the domain), explains the fact that the added value of an associated glider transect is not significant. 
These experiments combining existing and future observing systems, as well as numerical ensemble simulations, highlight the key issue of monitoring the whole water column in and close to river plumes (using gliders for example) and the efficiency of the surface high frequency sampling from FerryBoxes in macrotidal regions.

Keywords : Design of in situ observation network, Bay of Biscay, English Channel, glider, FerryBox 


\section{Introduction}

In the middle of the European Atlantic Arc, the Bay of Biscay and the English Channel encompass diverse coastal dynamical regions (Fig. 1). In the southern part, North of Spain, the continental shelf is very narrow and the coastal dynamics is mainly driven by the slope current and local upwellings. When we are travelling to the North along the French coasts, the continental shelf is becoming wider and the main rivers (Gironde, Loire, and Seine in the English Channel) have to be considered as major sources of freshwaters drawing the density gradients over the shelf. The widening shelf is under the influence of tides (Le Cann, 1990) which are shaping the circulation in the English Channel (Salomon and Breton, 1991, 1993). Finally, the Bay of Biscay and English Channel circulation is constrained by atmospheric forcings with a SOMA (September-October / March-April) seasonal response (Pingree et al., 1999).

This region, as most of coastal ocean regions, is under the pressure of the global change (climate and anthropogenic), which can be observed through the different in situ and remote observing systems (deCastro et al., 2009; Michel et al., 2009a;b; Costoya et al., 2015).

In this context, coastal existing networks (e.g. HOSEA - High frequency Observation network for the environment in coastal SEAs, SOMLIT - Service d'Observation en Milieu LITtoral) are mainly limited along the coast with a small offshore extent. They also mainly focus on surface observations (supplementing satellite observations) but few continuous measurements are dedicated to the whole water column while it has been observed that deep continental shelf waters are also changing (Gonzalez-Pola et al., 2005; GómezGesteira et al., 2013; Charria et al., 2014).

The following question is then becoming more and more crucial: How could we improve (i.e. optimize, develop, extend) existing networks for long term observations in such a dynamically contrasted region under the pressure of global change and in a challenging economic environment?

The present study aims at applying a quantitative method to design local observation arrays as part of a future integrated coastal network. Several approaches can be considered to carry out such design experiments (e.g. Schulz-Stellenfleth and Stanev, 2010; Fu et al., 2011), amont which Observing System Simulation Experiments (OSSE; e.g. Charney et al., 1969; Hackert et al., 1998; Kuo et al., 1998; Frolov et al., 2008; Lin et al., 2010) approaches using data assimilation platforms. In the case of the Bay of Biscay and the English Channel, the ArM (Array Modes) methodology (De Mey, 2014, pers.comm., available in the SANGOMA Tools http://www.data-assimilation.net/Tools/; Le Hénaff et al., 2009; Lamouroux et al., 2016) has been applied. This approach is based on ensemble numerical simulations without assimilating observations.

Two regions under two contrasted coastal dynamics have been considered:

- the vicinity of the Loire River plume strongly influenced by freshwater inputs (hereafter called Loire region - Fig. 1b),

- the Western English Channel with a circulation mainly driven by tides (hereafter called WEC region - Fig. 1c). 


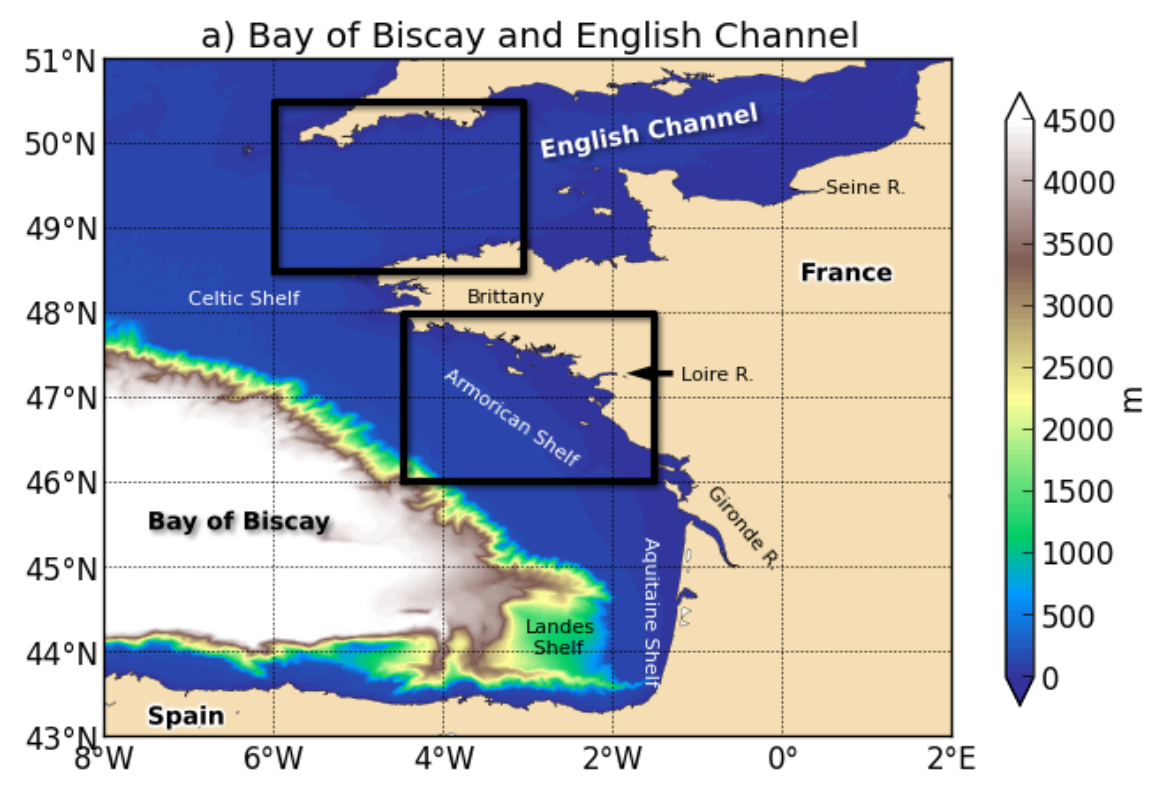

b) Loire region

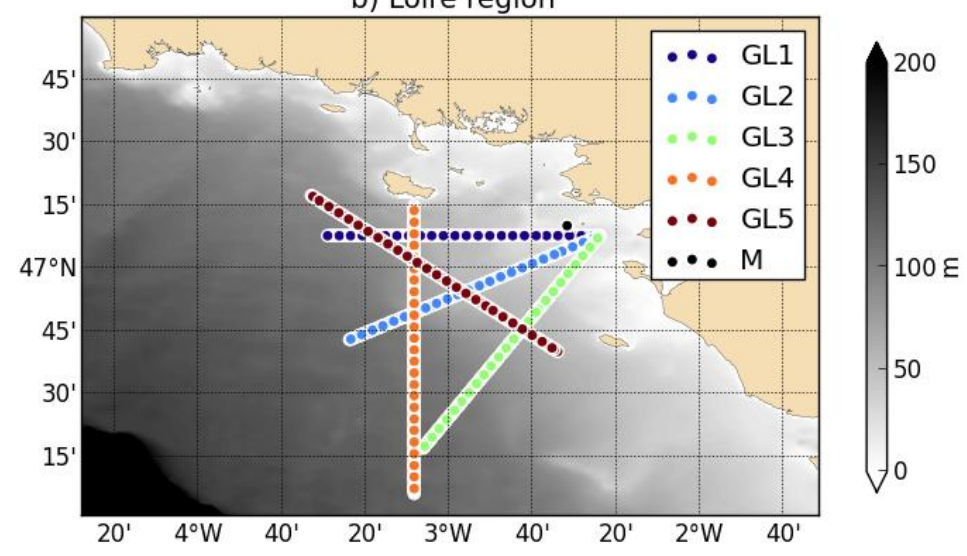

c) Western English Channel (WEC) region

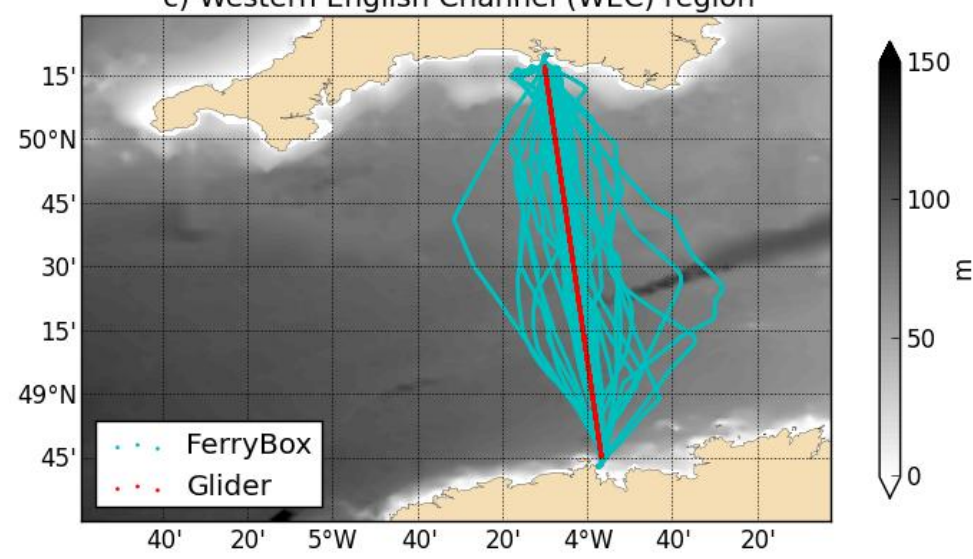

Figure 1: (a) Map and bathymetry of the Bay of Biscay and the English Channel, showing both subregions. (b) Subregion around the Loire River plume, with sketches of the mooring and glider sections considered (described in section 4.1). (c) Subregion in the Western English Channel (WEC), with localization of the FerryBox trajectories (blue) and the glider section (red) described in section 5.1 . 
The evolutions of existing coastal observation networks along the French coast which were considered in the recent years were mostly focused on improvements of the monitoring of main river plumes. On the basis of choices made in related ongoing projects (i.e. FP7 JERICO, http://www.jerico-fp7.eu/), the first area selected here is the Loire runoff region (Fig. 1b). This area is influenced by a large river plume with an average discharge around $900 \mathrm{~m}^{3}$ $\mathrm{s}^{-1}$ exceeding $3000 \mathrm{~m}^{3} \mathrm{~s}^{-1}$ in winter or early spring (Puillat et al., 2004). The plume spreads northwards and along shore except when runoffs are reduced and under southeastward winds conditions (Lazure and Jegou, 1998). The river freshwater signature can propagate until the entrance of the English Channel (Kelly-Gerreyn et al., 2006). The Loire region under the influence of the river exhibits stratified waters with a propagation mainly controlled by the wind. These conditions justify the deployment of an observation network monitoring subsurface layers. The assessed network is then combining a moored station with a glider endurance line. Based on capabilities of these platforms, five glider sections (along-shore and cross-shore) have been evaluated.

Another key area is the Western English Channel (WEC) region (Fig. 1c) where the circulation is tidally-driven (Salomon and Breton, 1991, 1993). The mean summer non-tidal zonal transport is lower than 0.2Sv (Hill et al., 2008). The vertical structure of the water column is contrasted between the Northern part stratified in summer (nWEC) and the southern part (sWEC) where it remains mixed during the whole year. These two main provinces are separated by a thermal front around 49.5 $\mathrm{N}$ (Marrec et al., 2013; Marrec et al., 2014). The WEC surface waters are sampled by a FerryBox system aboard MV Armorique, sailing between Roscoff (France) and Plymouth (UK) on a daily basis since May 2010. The experiment considered here mostly aims to estimate the added value of measurements in the water column using a glider along the FerryBox line, in addition to FerryBox measurements or as standalone measurements.

After introducing the ArM methodology (Section 2) and the ensemble model simulations (Section 3), the experiment in the Loire region is detailed and discussed in Section 4. The Section 5 is describing results for the WEC region before the general conclusions of these experiments (Section 6).

\section{ArM methodology}

The ArM methodology (De Mey, pers.comm., 2014) used here is a stochastic implementation approach described in Le Hénaff et al. (2009) and has also been described in detail by Lamouroux et al. (2016). A few key concepts of the method are briefly described below.

The methodology used here aims at providing an objective criterion for assessing the performance of a given observational array. In this framework, the methodology relies on the following paradigm: a "good" array (regardless the cost-considerations) is an array that can detect and - partly - correct the errors of a pre-existing (hereafter prior) estimate (e.g. from a model, a climatology). The criterion does not make any assumption on the form of the gain of a subsequent data assimilation step. An OSE/OSSE-type (Observing System Experiment - OSE; Observing System Simulation ExperimentsOSSE) criterion would assess an observational network in terms of the efficiency of that particular network at reducing objective error via a particular assimilation scheme, in effect testing both observability and controllability together. Instead, the ArM objective criterion centers on observability and 
detectability above ambient noise, and therefore holds intrinsic value, independently of the form of a possible assimilation scheme to be used (or not) as a later step.

Following this statement, some caveats have to be taken into account. The method is efficient to evaluate a network in the frame of the scales solved by the numerical system. For example, the domain, the spatial resolution and the temporal extent of the experiment will limit the processes for which the network is evaluated.

Let us define $y^{0}$, the vector of observations verifying $\mathbf{y}^{o}=H\left(\mathbf{x}^{t}\right)+\epsilon$, with $\mathbf{x}^{t}$ the "true" state (an augmented state vector over the time interval of interest; everything that will be shown below includes time as well as space in the definition of observations and prior state estimate), $H$ ( ) an observation operator (which is not necessarily linear - but for the sake of clarity we will consider a linearized operator $\mathbf{H}$ ), and Gaussian measurement error $\epsilon \in N(0, \mathbf{R})$, with $\mathbf{R}$ being the observational Error Covariance Matrix (hereafter ECM).

The purpose of the method is thus to examine whether and under which circumstances one particular array - defined by $(H, \mathbf{R})$ - can be said to be "objectively satisfactory", and whether, given two arrays, one of them can be said to be more efficient than the other.

The incremental "information" brought in by the array on top of the prior (part of this is new information, but part is noise) can be explored through the innovation vector $\mathbf{d}$ and its second-order statistics:

$$
\begin{gathered}
\mathbf{d} \equiv \mathbf{y}^{o}-\mathbf{y}^{t}=\mathbf{y}^{o}-H\left(\mathbf{x}^{f}\right) \approx \epsilon-\mathrm{H} \eta \\
\left\langle\mathbf{d d}^{T}\right\rangle=\mathbf{R}+\mathbf{H P}^{f} \mathbf{H}^{T}
\end{gathered}
$$

with $\eta \in N\left(0, \mathrm{P}^{f}\right)$ the error statistics associated with the prior estimate $\mathbf{x}^{f}$ defined as

$$
\mathbf{x}^{f}=\mathbf{x}^{t}+\eta
$$

Now intuitively, if $\mathbf{R}$ dominates in (2), the discrepancies between the observations and the model are mostly due to observational errors, and the observations are not being very useful. On the contrary, if $\mathrm{HP}^{f} \mathrm{H}^{T}$ (the so-called Representer Matrix - herefater RM) dominates, then most of the discrepancies are due to the prior state, and observations can be expected to be useful at identifying and correcting the prior state errors.

To formalize this first-approach criterion, we scale the innovation vector second-order statistics by $\mathbf{R}$, leading to:

$\mathbf{R}^{-1 / 2}\left\langle\mathbf{d d}^{T}\right\rangle \mathbf{R}^{-1 / 2}=\mathrm{I}+\chi$

$\chi=\mathbf{R}^{-1 / 2} \mathbf{H P}^{f} \mathbf{H}^{T} \mathbf{R}^{-1 / 2}$

$\chi=\mu \sigma \mu^{T}$

The above criterion thus comes back to comparing (in (4)) the eigenspectrum $\sigma$ of $\chi$, the "projected" RM, to the eigenspectrum of $\mathbf{I}$ (which is trivial and equal to 1), i.e. counting how many eigenvalues in (4) lie above 1 . The corresponding array modes $\mu$ will be the "detectable" error modes above the observational noise floor. The number of eigenvalues above 1 can thus be used to compare whole arrays to each other. However, the error degrees of freedom detected by two very different arrays can also widely differ in nature. 
Consequently, this eigenvalues-based criterion should be completed by the examination of (1) the array modes $\boldsymbol{\mu}$, as well as of (2) the associated modal representers, $\boldsymbol{\rho}_{\boldsymbol{\mu}}$, introduced by Le Hénaff et al. (2009), as an extension to the classic notion of representers (the influence functions of individual observations), and defined as:

$\rho_{\mu}=\mathrm{P}^{f} \mathrm{H}^{T} \mathrm{R}^{-1 / 2} \boldsymbol{\mu}$

These modal representers correspond to the projection of the array modes onto the physical space, and allow the examination of the theoretical correction which would be applied by a particular array mode if assimilation was eventually performed.

As first stated at the beginning of this section, we used in this study a stochastic implementation of the above concepts, where the prior ECM is approximated by means of an Ensemble (itself generated by perturbing error sources via key parameters). The ArM stochastic method is detailed in Lamouroux et al. (2016) and is available in the SANGOMA Tools (De Mey, pers. comm., 2014; http://www.data-assimilation.net/Tools/).

\section{Model and observation uncertainties}

An ensemble of 50 perturbed simulations carried out with the MARS3D model as part of the PREVIMER project (Lazure and Dumas, 2008; Duhaut et al., 2008) has been used to estimate the model ("prior") Error Covariance Matrix. The ensemble configuration was based on different combined sources of errors:

- the atmospheric forcings, which have been modelled through a 50-member ensemble of gaussian-perturbed atmospheric fields (pressure at Sea Level, 10mwind, Surface Heat Fluxes, 2m-temperature) provided by ECMWF;

- specific model parameters: the bottom friction coefficient, the turbulent-closure coefficient and the light-extinction coefficient, which were slightly perturbed following a Gaussian distribution. Those parameters were retained since they have been shown to have a significant impact on the model results, and are partly uncorrelated.

The statistical consistency of this 50 perturbed-simulations ensemble has been verified in details in Lamouroux et al. (2016). The simulated period extends from May 3rd to May 25th, 2006, representing a typical spring situation.

The ArM method requires an estimate of the observational ECM. In these experiments, our sampled variables are temperature and salinity. Based on previous experiments (e.g. Le Hénaff et al., 2009; Kourafalou et al., 2015; Lamouroux et al., 2016) and the observed dynamics in these regions, observation errors (including the sensor accuracy and the representativity error, linked to small scale features incorrectly represented in the model, or to the sampling protocol) have been set to $0.3^{\circ} \mathrm{C}$ for the temperature and 0.25 for the salinity. Furthermore, the observational ECM was considered diagonal.

\section{Loire experiment}

\subsection{Experimental framework and model uncertainty}

The first experiment aims to assess a potential future observation network designed to monitor the temperature and salinity variability in the Loire River plume. This plume is one of the major river runoffs in the Bay of Biscay and these fluxes feed the freshwater content over the shelf in the Bay of Biscay and constrain stratification there. 
The studied domain is limited around the Loire plume extent to avoid spurious covariances in the method, which could lead to an overestimation of the observing system efficiency.

The experiment explores 5 observation networks (Fig. 2a):

- $\mathrm{M}$ : a single moored station monitoring surface temperature and salinity close to the river mouth,

- $M+G L 1, M+G L 2, M+G L 3:$ the moored station associated with cross-shore glider sections,

- M+GL4: the moored station and an along-shore glider section front of Loire River,

- M+GL5: the moored station and a North-South glider section South of Belle-lle island.

The glider speeds along the fictitious sections are ranging from 0.32 to $0.48 \mathrm{~m} \mathrm{~s}^{-1}$ (corresponding to travelled distance from $474 \mathrm{~km}$ to $698 \mathrm{~km}$ in 17 days) with a maximum depth around $120 \mathrm{~m}$.

The experimental glider sections under evaluation have been designed based on the typical spatio-temporal scales of our ensemble variance (Fig. 2). Regarding temperature, most of the ensemble variance in the vicinity of the Loire River plume can be detected in shallow waters with values exceeding $0.4^{\circ} \mathrm{C}$ where model errors are larger. The extent of these error patterns is fluctuating during the period with a dominant propagation direction to the Northern part of the domain. The two dates displayed in Fig. 2a (11th May) and 2b (18th May) show an example of two contrasted situations. At depth (Fig. $2 \mathrm{c}$ to $2 \mathrm{~h}$ ), below every glider sections, two error cells can be described. In surface layers $(0-10 \mathrm{~m}$ depth), due to the uncertainties in the river plume, errors appear in every glider sections. A subsurface error cell is also detected around $20 \mathrm{~m}$ depth with a lower intensity $\left(<0.25^{\circ} \mathrm{C}\right)$. This subsurface pattern does not present the same shape depending on the position and the date. For example, this structure does not appear in GL3 section during the 11th May (Fig. 2e). At the opposite the 18th May (Fig. 2h), the subsurface maximum extends from 20 to $40 \mathrm{~m}$ depth. This subsurface pattern is attributed to the uncertainties in the thermocline depth in ensemble simulations.

Regarding salinity (Fig. 3), the ensemble variance locally exceeds 0.3 psu and is shaped as filaments related to the river plume extent. These filaments, constantly evolving during the simulated period are mainly advected to the North. These error patterns can be linked to the uncertainties along the edge of the freshwater plume extending northward during this season (Lazure and Jegou, 1998). Model error filaments have a vertical extent to $10 \mathrm{~m}$ depth related to the uncertainty in the thickness of the freshwater plume. These structures represent most of the ensemble variance visible along glider sections (Fig. $3 \mathrm{c}$ to $3 \mathrm{~h}$ ). Outside this variance cell, estimated errors are lower than $0.1 \mathrm{psu}$. 

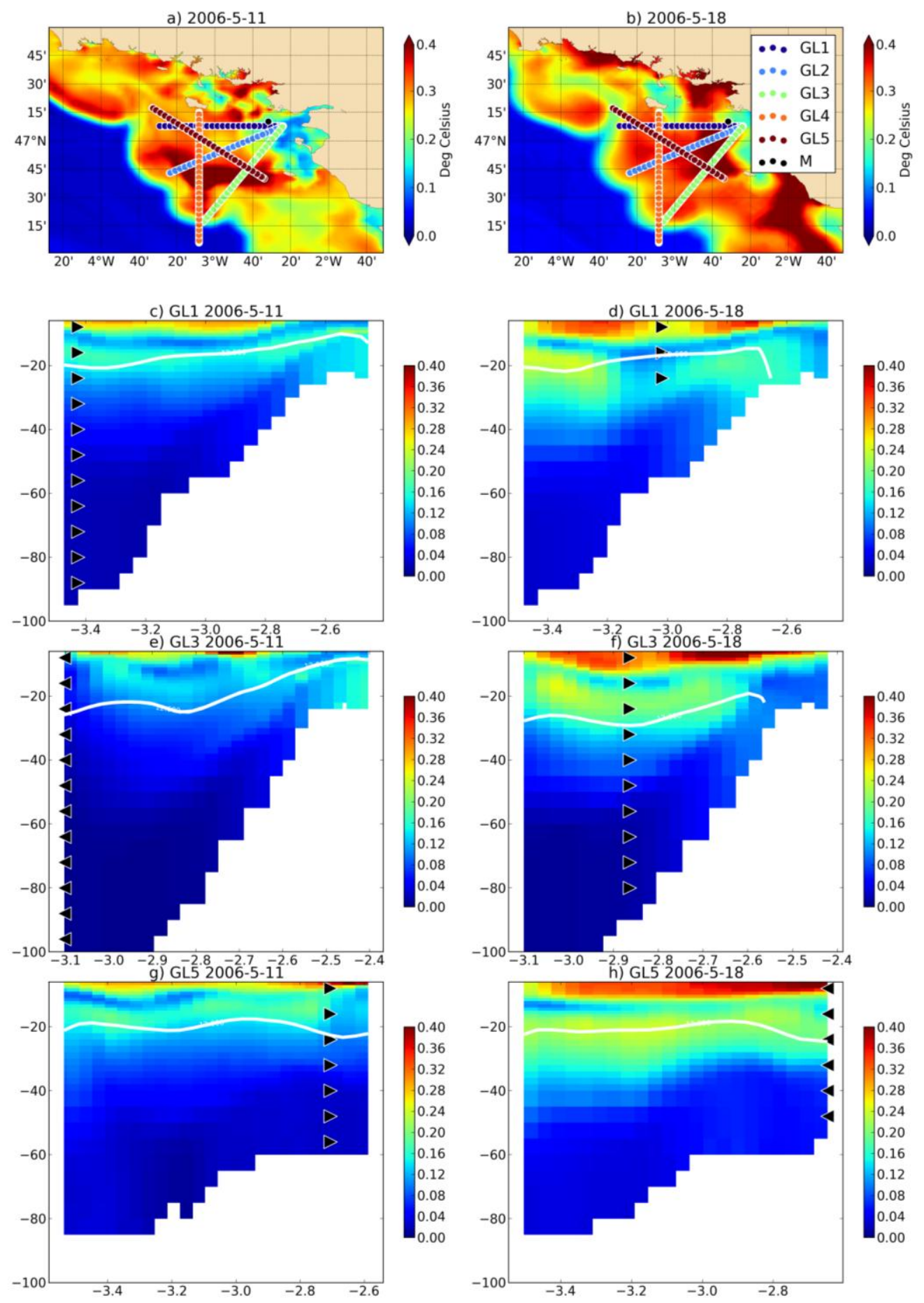

Figure 2: Temperature ensemble standard deviation close to Loire River plume the 11th May (a, c, e, $\mathrm{g}$ ) and the 18th May (b, d, f, h) for the surface $(\mathrm{a}, \mathrm{b})$, and along the GL1 (c, d), GL3 (e, f) and GL5 (g, h) sections. White lines are the isotherm representing the thermocline position $\left(12.6^{\circ} \mathrm{C}\right.$ except for $\mathrm{a}$ and $\mathrm{e}$ where the value is $12^{\circ} \mathrm{C}$ ). 

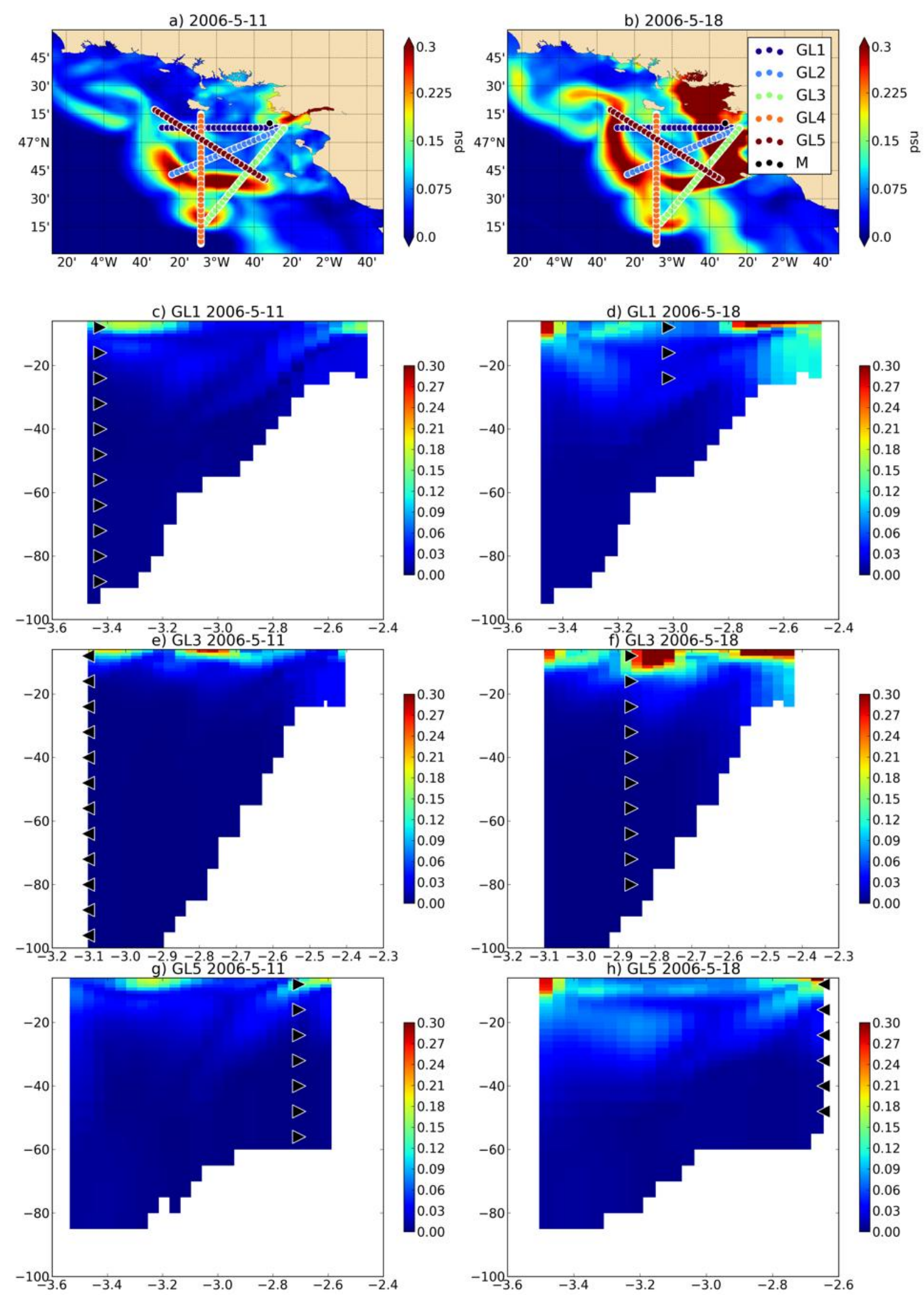

Figure 3: Salinity ensemble standard deviation close to Loire River plume the 11th May (a, c, e, g) and the 18th May (b, d, f, h) for the surface $(a, b)$, and along the GL1 (c, d), GL3 (e, f) and GL5 (g, h) sections. 


\subsection{Results}

\subsubsection{A global indicator: the ArM eigenspectrum}

Based on the ArM methodology, a first ranking can be proposed. Within the mathematical framework described in Section 2, the number of detected degrees of freedom (dof) by the observing network can be estimated by counting how many eigenvalues lie above 1 in the ArM eigenspectrum (see Eq. 4).

Two main results can be deduced from the ArM eigenspectrum (Fig. 4). First, a clear expected gap between observing network based on a single mooring (11 detected dof) and other networks combining this mooring with gliders (38 to 41 detected dof) is observed. This result is directly related to the fact that using gliders, a larger range of model error structures can be sampled.

The second major and unexpected result (Fig. 4b) is related to the degrees of freedom detected in the case of the five glider sections tested for this experiment. Indeed, the number of detected dof does not seem sensitive to the choice of the glider section (along shore, cross shore or meridional section). All networks ranges from 38 to 41 detected dof. Glider 4 (North-South section) and 5 (alongshore section) appear as the most efficient with 41 detected dof. At the opposite, Glider 2 (intermediate cross-shore section) seems slightly less efficient (38 detected dof). However differences in the number of detected dof are very small and do not allow inferring a significant difference in these glider section efficiencies to constrain model uncertainties. 

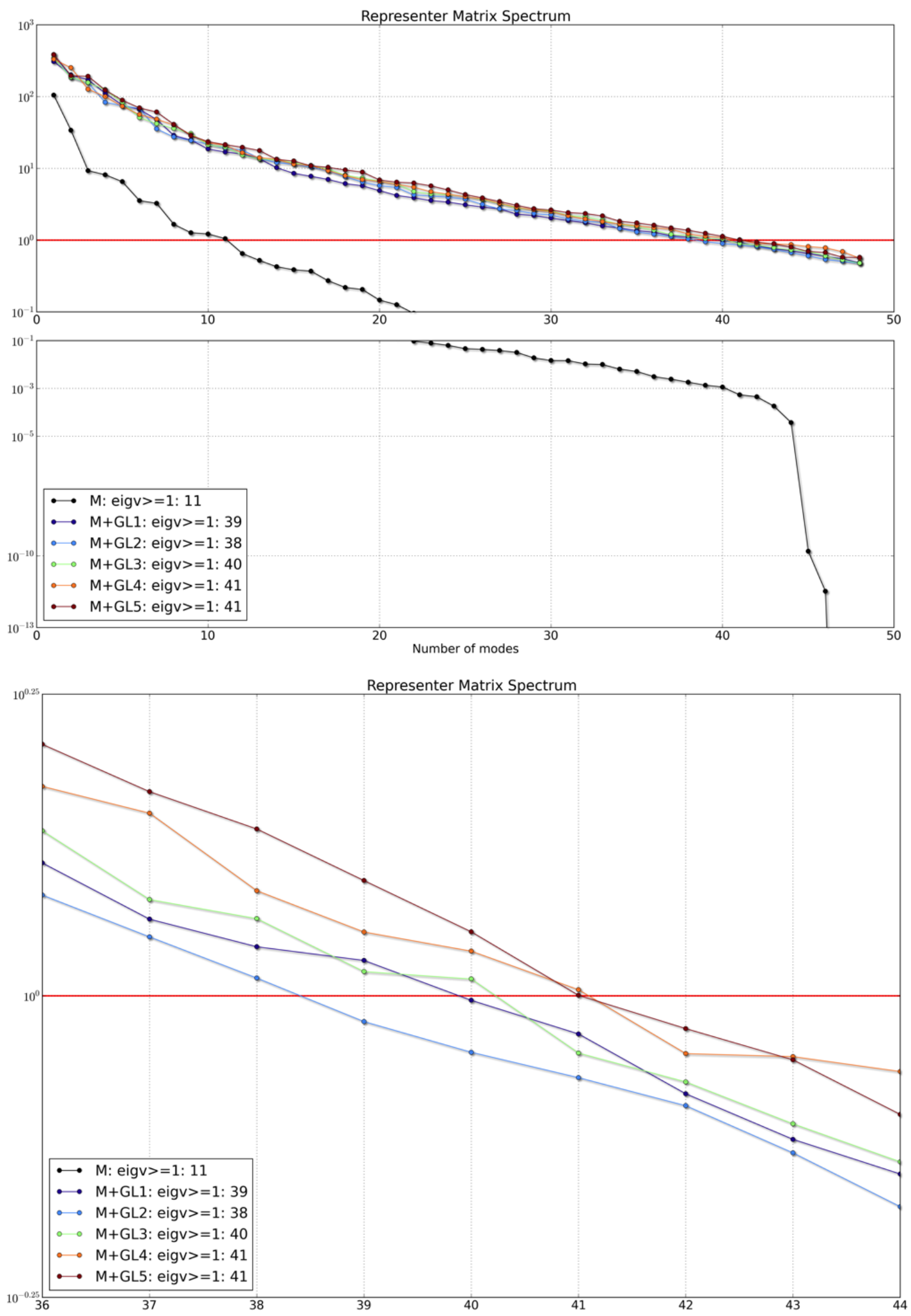

Figure 4: (Top) Representer Matrix Spectrum for all the analysed networks (M - Mooring, $M+G L^{*}$ Mooring and $\mathrm{GL}^{*}$ corresponding glider section) - the number of eigenvalue larger than 1 is detailed on the figures. (Bottom) Zoom for modes 36 to 44 - the only glider-based configurations are represented. 


\subsubsection{The glider view: the ArM eigenvectors}

Further investigations are dedicated to spatial and temporal structures of the model error modes detected by the observing network. A dedicated diagnostic, based on the ArM eigenvectors $\boldsymbol{\mu}$ (see Eq. (4)), hereafter called Array Modes, allows estimating the capability of a given network to describe model error modes in the observation space.

Fig. 5 gives an overview of the first Array Mode in temperature and salinity, along the GL1 section. The ensemble standard deviation in temperature (Fig. 5a) increases with time, reaching maximum values during the third transect at surface and a subsurface maximum between $20 \mathrm{~m}$ and $40 \mathrm{~m}$ depth during the last transect. These main features can also be highlighted in the corresponding first Temperature Array Mode (Fig. 5b), confirming that the glider is able to detect these model error modes. Note that the Fig. $5 \mathrm{~b}$ only represents the first Array Mode, which samples the most dominant error patterns. Finer structures are then detected by higher-order Array Modes (not shown). Regarding salinity (Fig. 5c), model errors are confined in surface layers during the first three transects, before they grow up and extend until $40 \mathrm{~m}$ depth during the last transect. Note that these latter error structures are linked to the signature of perturbations at the edge of fine scale patterns (e.g. river plume, filaments, lenses of low salinity waters). The salinity model error maximum is "sampled" near the coast, between the third and the last transects, and corresponds to the signature of the filament-shaped salinity error structures associated with the perturbations in the Loire River plume front. The corresponding first Array Mode (Fig. 5d) evidences these main patterns highlighted in the ensemble standard deviation, such as the surface maxima progressively deepening during the simulated period, the coastal maxima near the Loire mouth, as well as the contrasted structures during the fourth transect. 

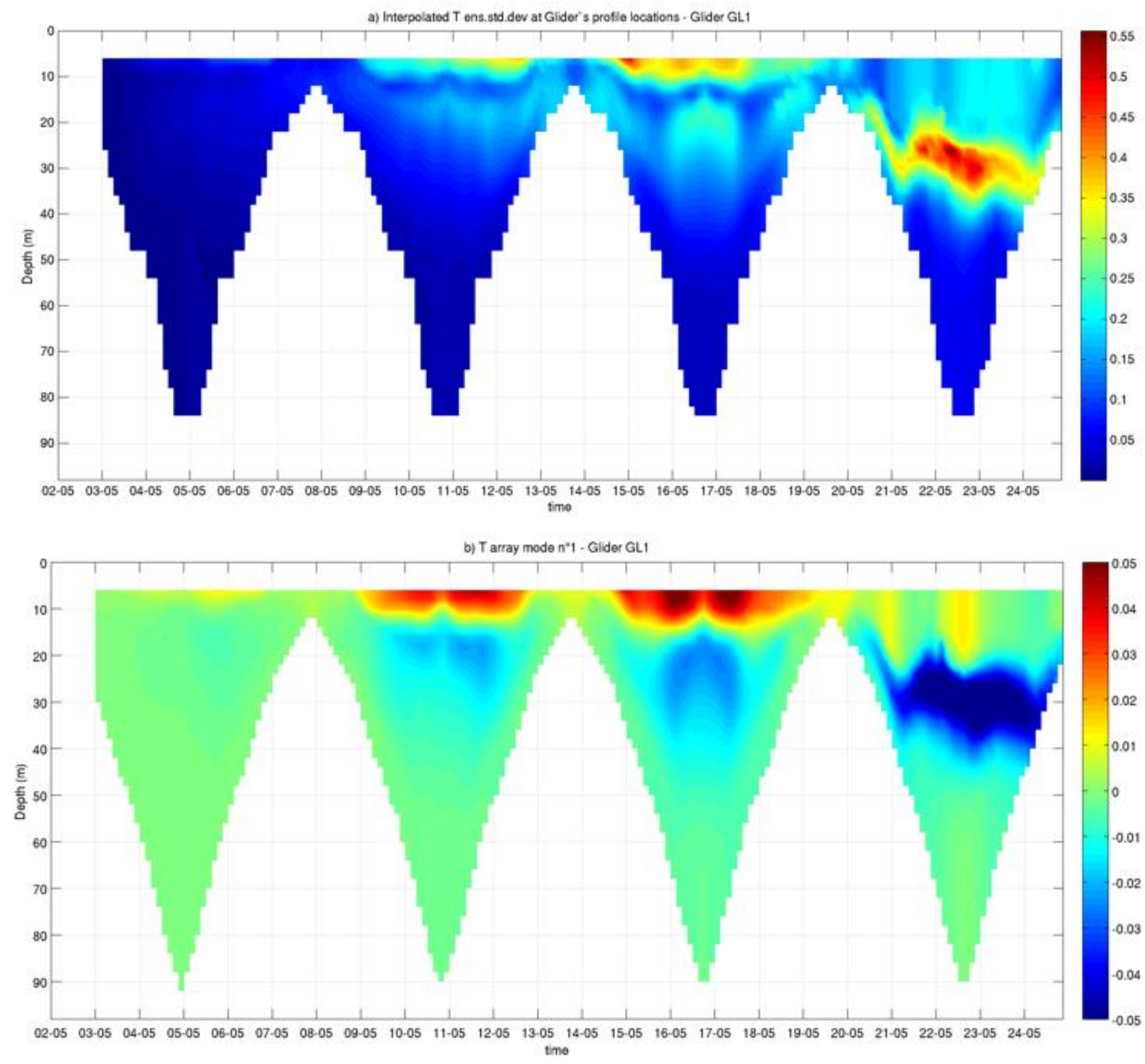

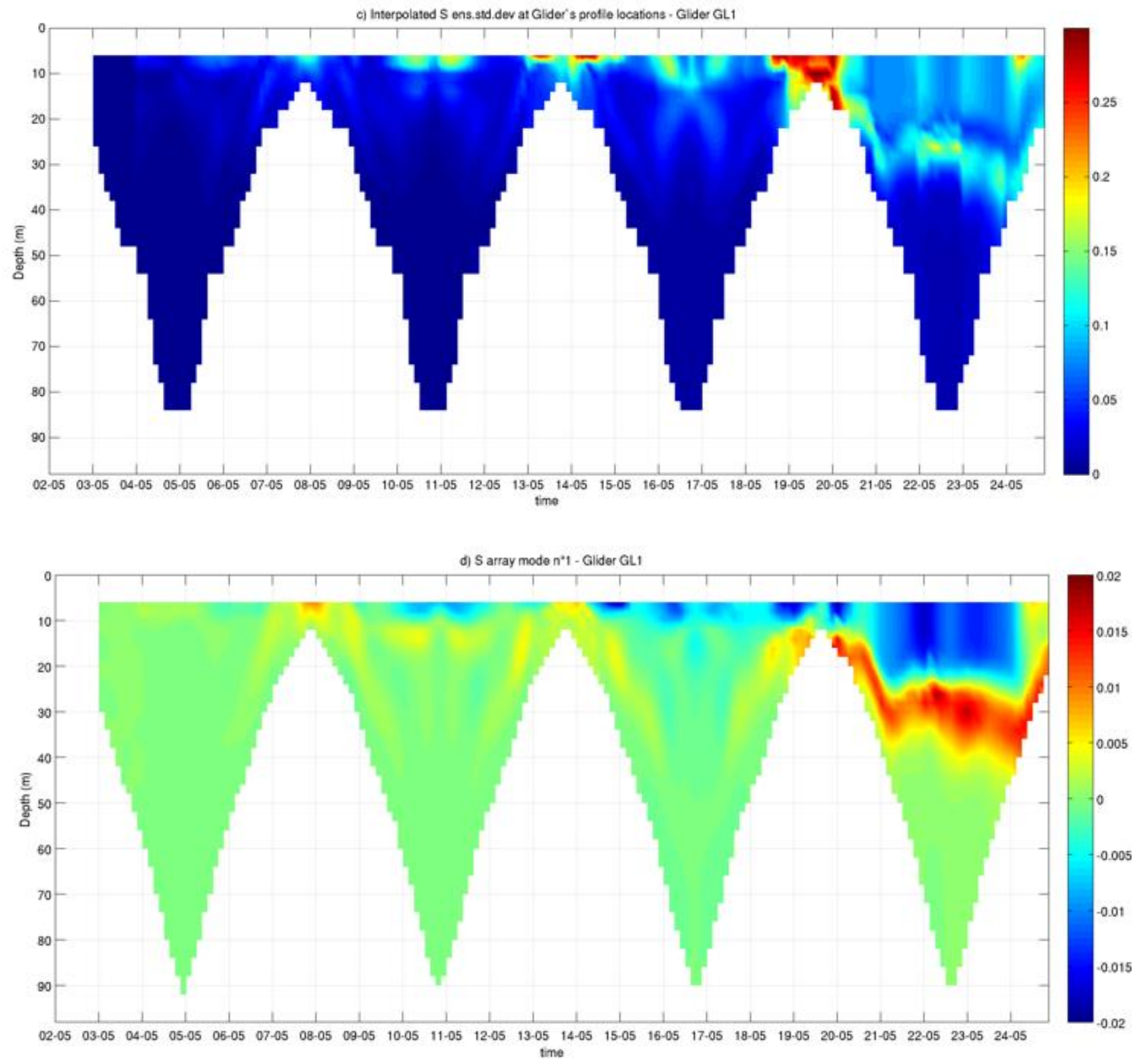

Figure 5: Example of Temperature (a) and Salinity (c) ensemble standard deviation projected on GL1 glider position for the whole analysed period. For the same glider section (GL1), corresponding first array mode for Temperature (b) and Salinity (d) are displayed.

These comparisons have been extended to other glider sections (not shown) and similar agreements between Array Modes and ensemble standard deviation can be drawn up.

\subsubsection{The theoretical correction: the ArM modal representers}

The modal representers, as defined in Eq. (5), are now explored and compared to the model error structures, approximated by the model ensemble standard deviation. Indeed, these modal representers quantify the impact of a given observation network onto the model field in terms of model error correction - if the associated observations were assimilated in a further step. The efficiency of this observation network is thus all the greater as the modal representers reproduce patterns of maximum ensemble variance. 
Fig. 6 shows the first and the second temperature and salinity modal representers for the GL1-based and GL5-based sections, during the 18th May 2006. As noted above, they compare to the model ensemble standard deviation at the same date (in Fig. $2 b$ for temperature and $3 \mathrm{~b}$ for salinity). Regarding temperature, the first modal representers are similar for both networks (GL1 and GL5 - Fig. 6a, c, e, g). A dipole with larger values in the northern part of the domain is highlighted in temperature (Fig. 6a, c), mirroring the main model error structures at this date (Fig. 2b). The 2nd modal representer is different in both displayed sections. In GL1 (Fig. 6b), the 2nd modal representer heightens the error structure from the river plume with an influence including the inner shelf closer to the coast. When it comes to the GL5 (Fig. 6d), due to the along-shore orientation of the glider section, the associated 2nd modal representer preferentially extends alongshore and does not properly detect the coastal error structure. Also note that, at this date, the mooring does not even sample this northern error structure, and thus does not bring any useful information.

Regarding salinity, the 1st and 2nd modal representers are similar in GL1-based configuration, and evidence the expected influence of the assimilation in the fresher and frontal parts of the river plume. The 1st modal representers have similar patterns for both configurations. The 2nd modal representers appear to be more sensitive to the glider trajectory: the one associated with the cross-shore GL1 network (Fig. 6f) is more intense in the region close to the river mouth, since the GL1 section effectively samples this region. On the contrary, in this latter region, the 2 nd modal representer associated with the alongshore GL5 network appears to be more attenuated (Fig. 6h).

Similar matchings are observed between the model error structures and the modal representers associated with the GL2-, GL3- and GL4-based networks. In particular, the salinity filament-shaped structure, as well as the temperature central pattern, are detected by each glider-based network. It is also noteworthy that those matchings are effective at various dates during the studied period. By contrast - but as expected - the modal representers associated with the only moored station are significantly attenuated, in agreement with the limited number of degrees of freedom constrained by this mooring.

This modal representer analysis confirms the ability of the various glider-based networks to monitor the river plume dynamics during this spring season. 

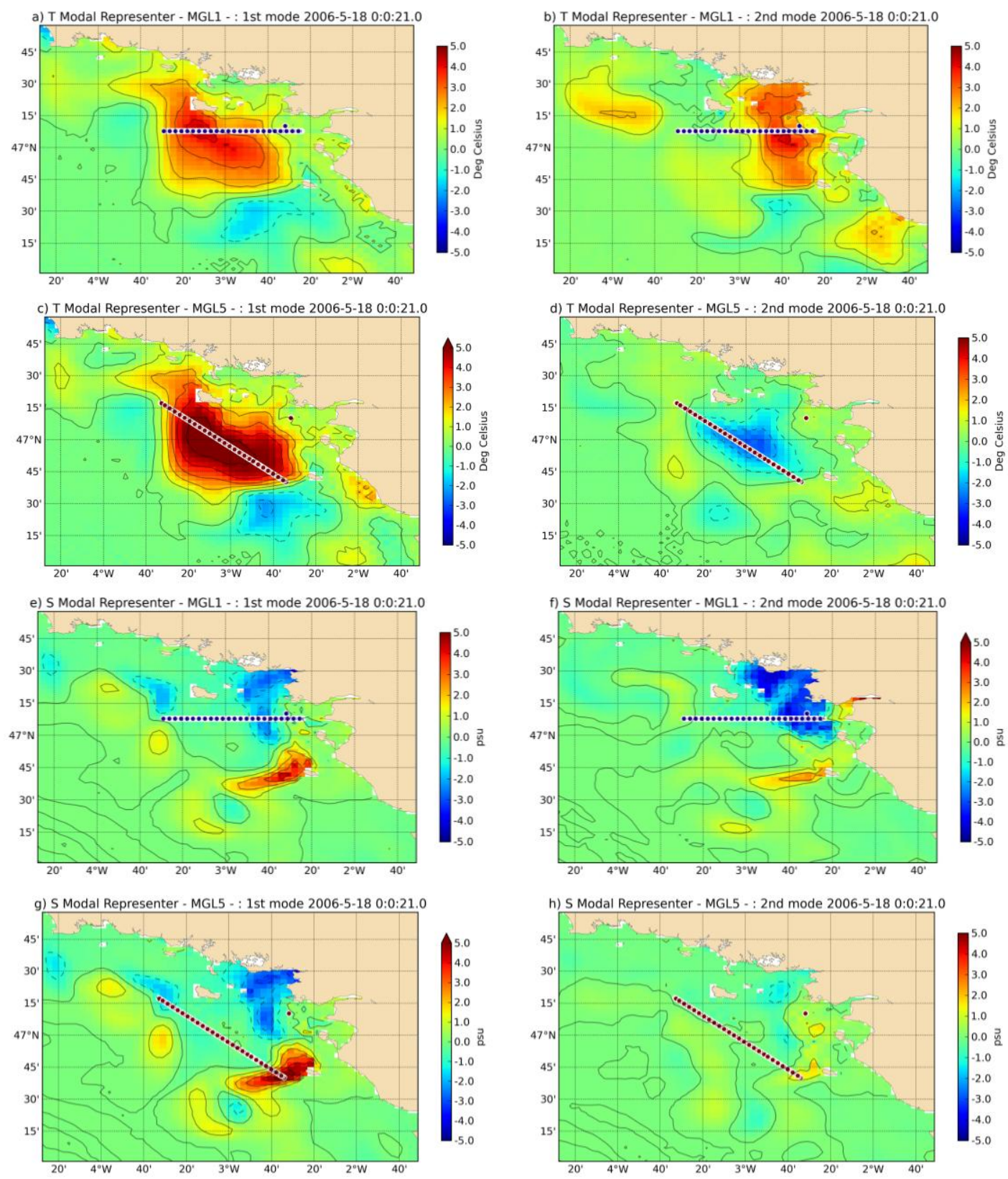

Figure 6: Illustration of Temperature $(a, b)$ and Salinity (c, d) modal representers for the first two modes (1st mode - left; 2nd mode - right) for the GL1 (a, c) and GL5 (b, d) networks for the 18th May 2006.

\subsection{Concluding remarks in the Loire River plume region}

The analysis of observation networks combining a moored station and different glider sections has revealed expected and unexpected conclusions. Indeed, as expected, adding a glider endurance line in the area of the Loire River plume significantly increases the range of monitored processes and, by extension, allows a better sampling of the model uncertainties which would be thus effectively controlled by data assimilation. The various indicators have shown that along-shore and meridional glider sections (GL4 and GL5) bring some efficiency to the network. However, the performances of the cross-shore glider sections (GL1, GL2 and GL3) have been shown to be similar - or slightly poorer. Considering that the spreading direction of the plume is mainly northward, these results were unanticipated. 
Nevertheless, gliders endurance lines appear then as a valuable option to extend the observation networks in the Loire region in order to follow the evolutions of the extended river plume.

\section{Western English Channel Experiment}

\subsection{Experimental framework and model uncertainty}

The second experiment is focused in Western English Channel (WEC), where tidal currents are dominant (Fig. 7). In this area, the surface hydrodynamics is already sampled by a FerryBox installed on MV Armorique since May 2010, and routing from Roscoff (France) to Plymouth (UK). Thus, the experiment described in this section has been designed to assess the possible improvements brought by additional observations in the water column. A virtual glider section (Fig. 7) has then been defined to play the role of the underwater autonomous observer.

Three observation network configurations have been analysed:

- a network with the FerryBox only (FB),

- a network with a single glider (GL),

- a network combining FerryBox and glider section (GL+FB).

The FerryBox crosses the English Channel 2 to 3 times per day (5h per transect) when the glider needs 4 days to connect Roscoff (France) to Plymouth (UK).

For this region, two variables (temperature and salinity) are considered as in the previous experiment with similar observation errors $\left(0.3^{\circ} \mathrm{C}\right.$ for temperature and 0.25 for salinity). 


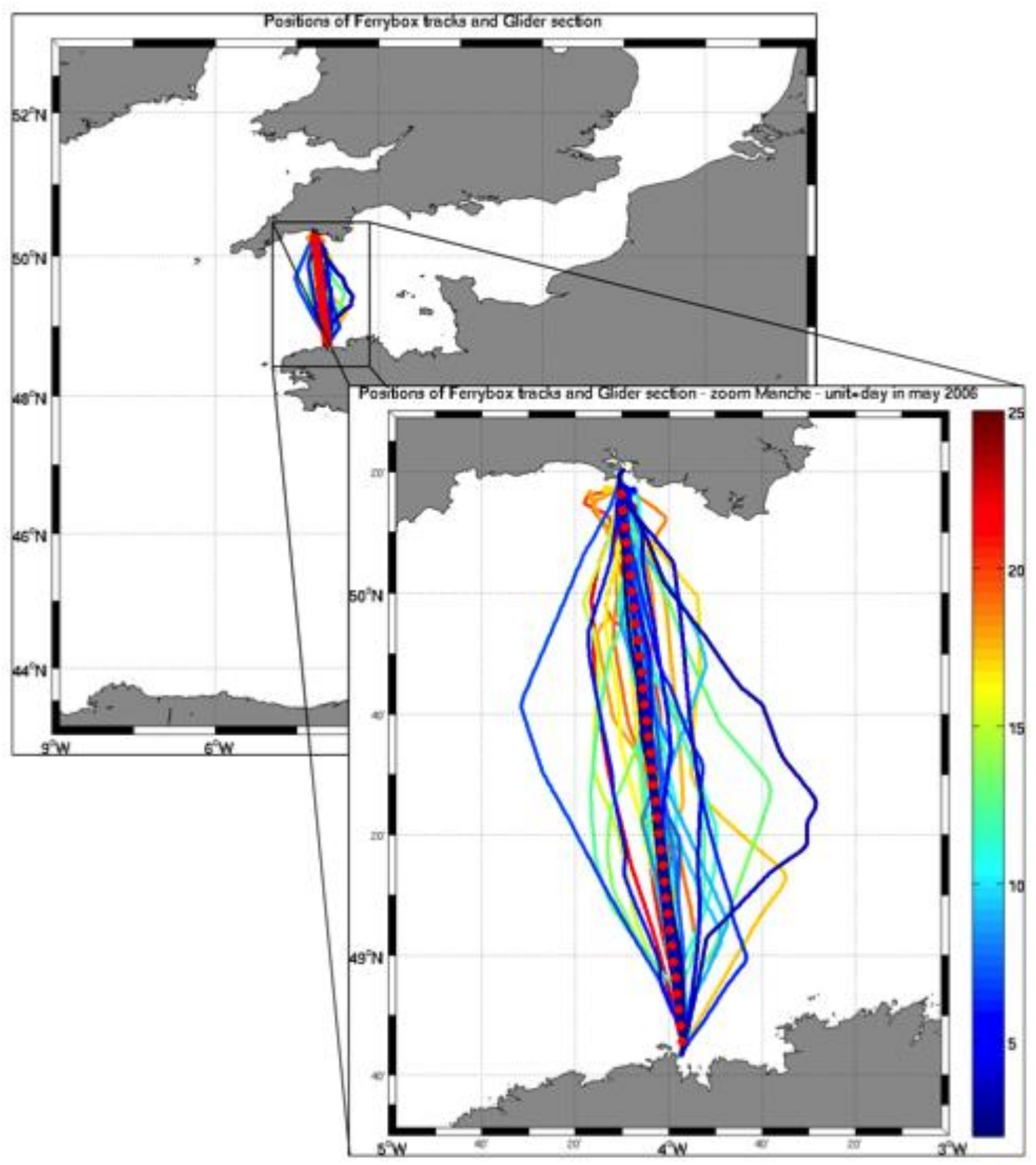

Figure 7: Map of FerryBox tracks and glider section considered in the analysis.

The model ensemble standard deviation at the surface, for the temperature (Fig. 8a) and the salinity (Fig. 8b), is characterized by a maximum (around $0.25^{\circ} \mathrm{C}$ in temperature and 0.015 in salinity) located between $49^{\circ} \mathrm{N}$ and $49.5^{\circ} \mathrm{N}$. This error structure is related to the uncertainties in the position of the thermal front between the two main provinces (mixed in the South and stratified in the North), as described in Marrec et al. (2013). This pattern is observed during the first part of the period until the 17 May. Then, the maximum extends to the North before decreasing during the last two days (20 and 21 May) of the period.

At depth, the error cell has a signature as a subsurface layer between 10 and $20 \mathrm{~m}$ depth (Fig. 8c). In salinity, uncertainties are very small below surface layers (Fig. 8d). The vertical structure is following a temporal evolution related to the surface dynamics with a subsurface intensity proportional to the front intensity at surface. 

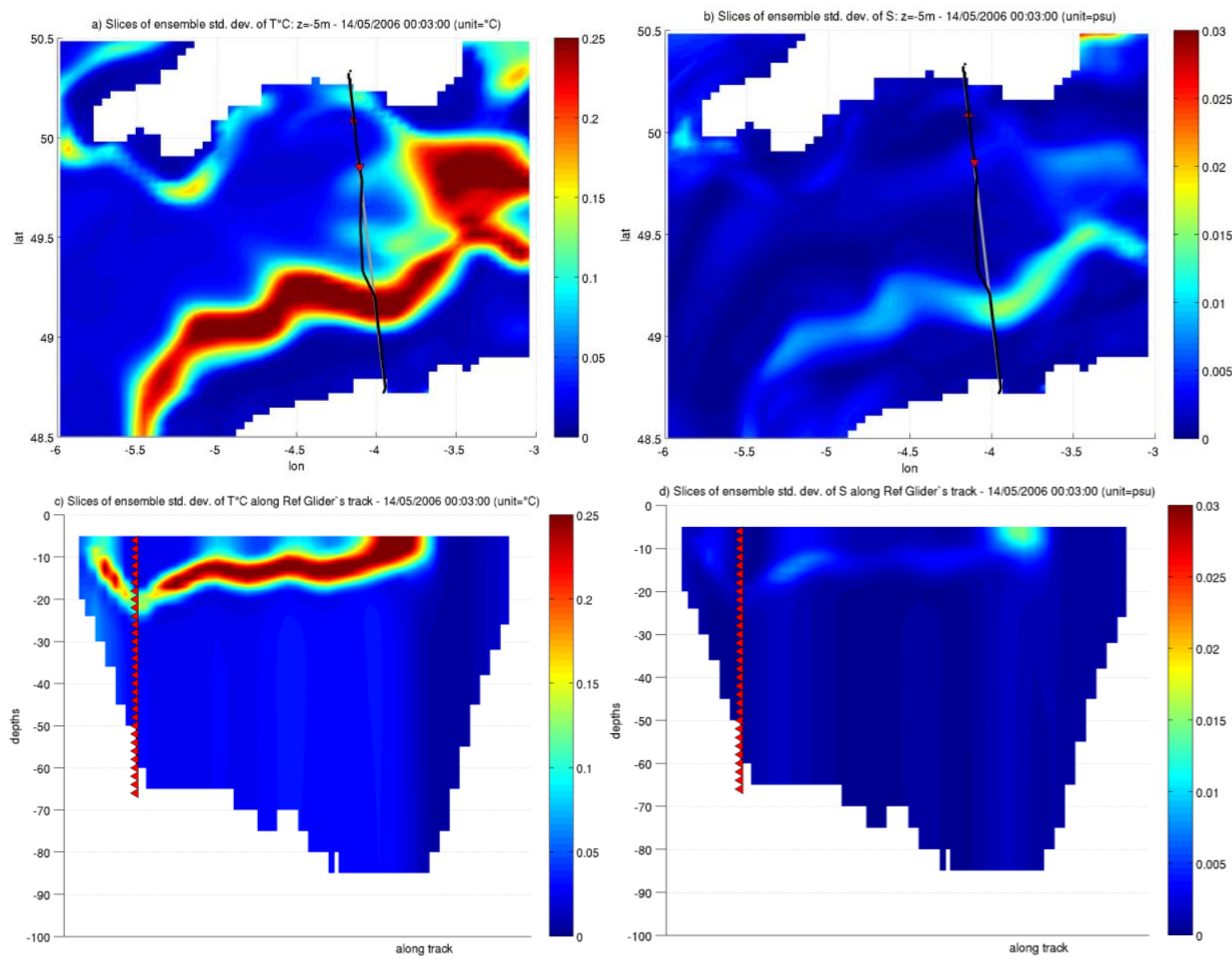

Figure 8: Temperature (a, c) and Salinity (b, d) ensemble standard deviation for the 14th May 2006 in surface layer $(a, b)$ and along the glider section (c, d). On (a,b), the black line indicates the FerryBox trajectory, while the grey line localizes the virtual glider section, both at the considered date. The red triangles indicate the position of the FerryBox and the Glider, as well as their displacement direction.

\subsection{Results}

\subsubsection{ArM eigenspectrum}

The ArM eigenspectrum for the three scenarios detailed in section 5.1 is displayed in Fig. 9. To assess the efficiency of the network, as in the previous experiment, eigenvalues larger than 1 have to be considered and counted. In the WEC experiment, we observe that the most efficient network is logically the network collecting the larger number of observations, i.e. the one based on the glider and FerryBox (GL+FB). This configuration is associated with 27 eigenvalues larger than 1 . However, it is noteworthy that results for the only-FerryBox network are very close (24 eigenvalues larger than 1), when the network based on a single glider only constrains 11 degrees of freedom of the observed system.

This indicator highlights that a glider deployed in this region, as a complement to the already existent only-FerryBox network, does not improve significantly the performances of this latter. These poor capabilities of the glider can be explained by its limited speed in a region where the ocean dynamics is mainly tidally-driven, with a most energetic semi-diurnal component. Furthermore, since most of the model error cells have a signature in surface during the period, the high frequency sampling of the surface layer, allows the FerryBox to 
capture most of these model error structures, and reinforces therefore its surface observation efficiency.

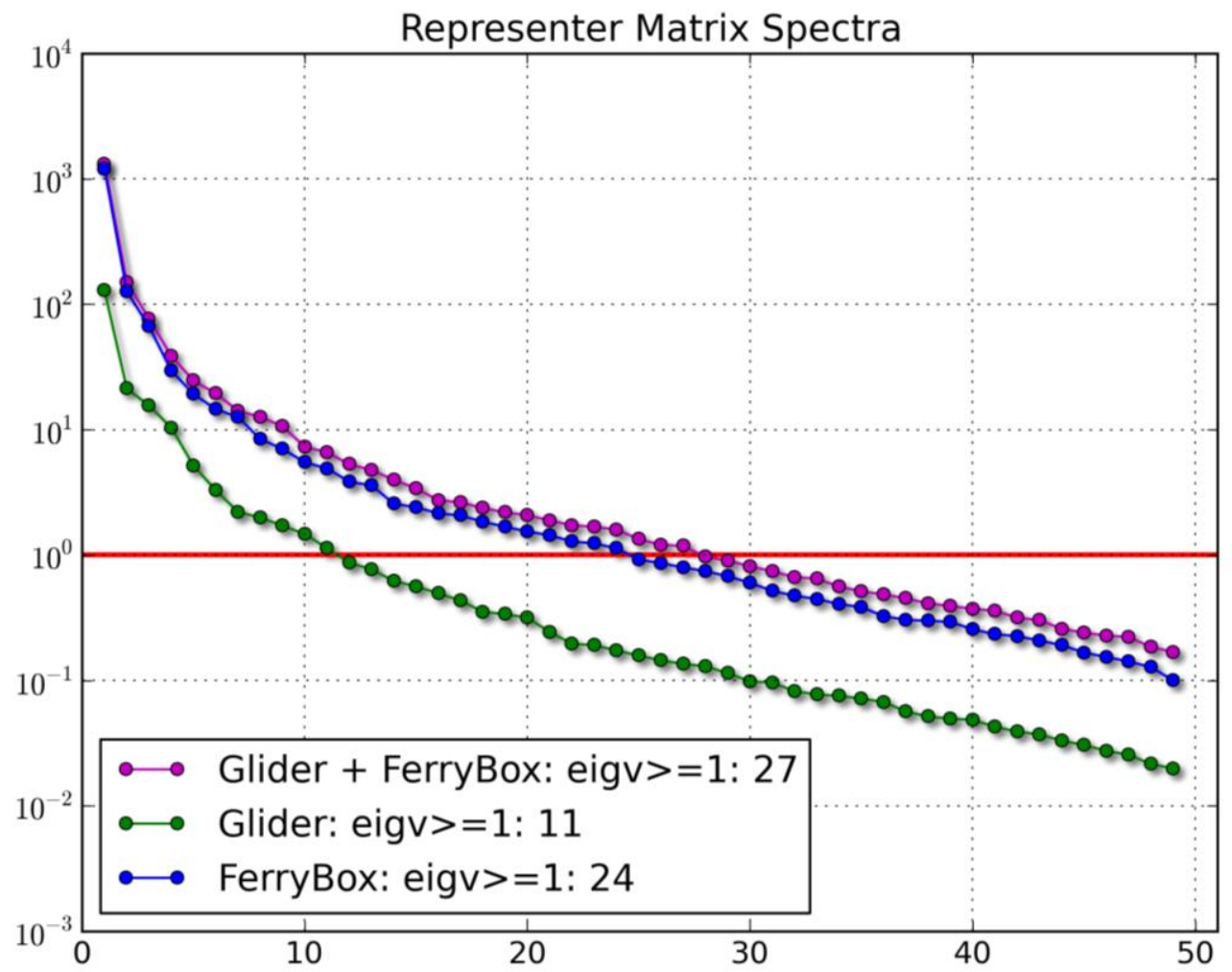

Figure 9: Representer Matrix Spectrum for the three analysed observing network in the western english Channel (FerryBox only, Glider only, FerryBox and Glider). Number of eigenvalues larger than 1 are displayed on the figure.

\subsubsection{ArM modal representers}

Modal representers structures and values (Fig. 10) confirm the capacity of the FerryBox observations to efficiently constrain the model error cells. (Fig. 10b and d) show that the structures and amplitudes of the modal representers associated with the FerryBox configuration are largely coherent with the model ensemble standard deviation (Fig. 8). Indeed, the frontal pattern, as the dominant structure in the model uncertainty, is efficiently described from the very first modal representer (Fig. 10b, d).

By contrast, the structures and values are significantly limited when it comes to the single glider modal representers (Fig. 10a, c). In that case, modal representer values are more than twice weaker than the ones associated with the FerryBox+glider modal representers. Therefore, this confirms the results brought in light by the ArM eigenspectrum criterion.

It is also noteworthy that the full observing system (FerryBox + glider) efficiency is very similar to the one estimated for the only FerryBox network, as the corresponding modal representers are very close in both configurations.

Similar results are obtained when exploring other time steps as well as other depths. 

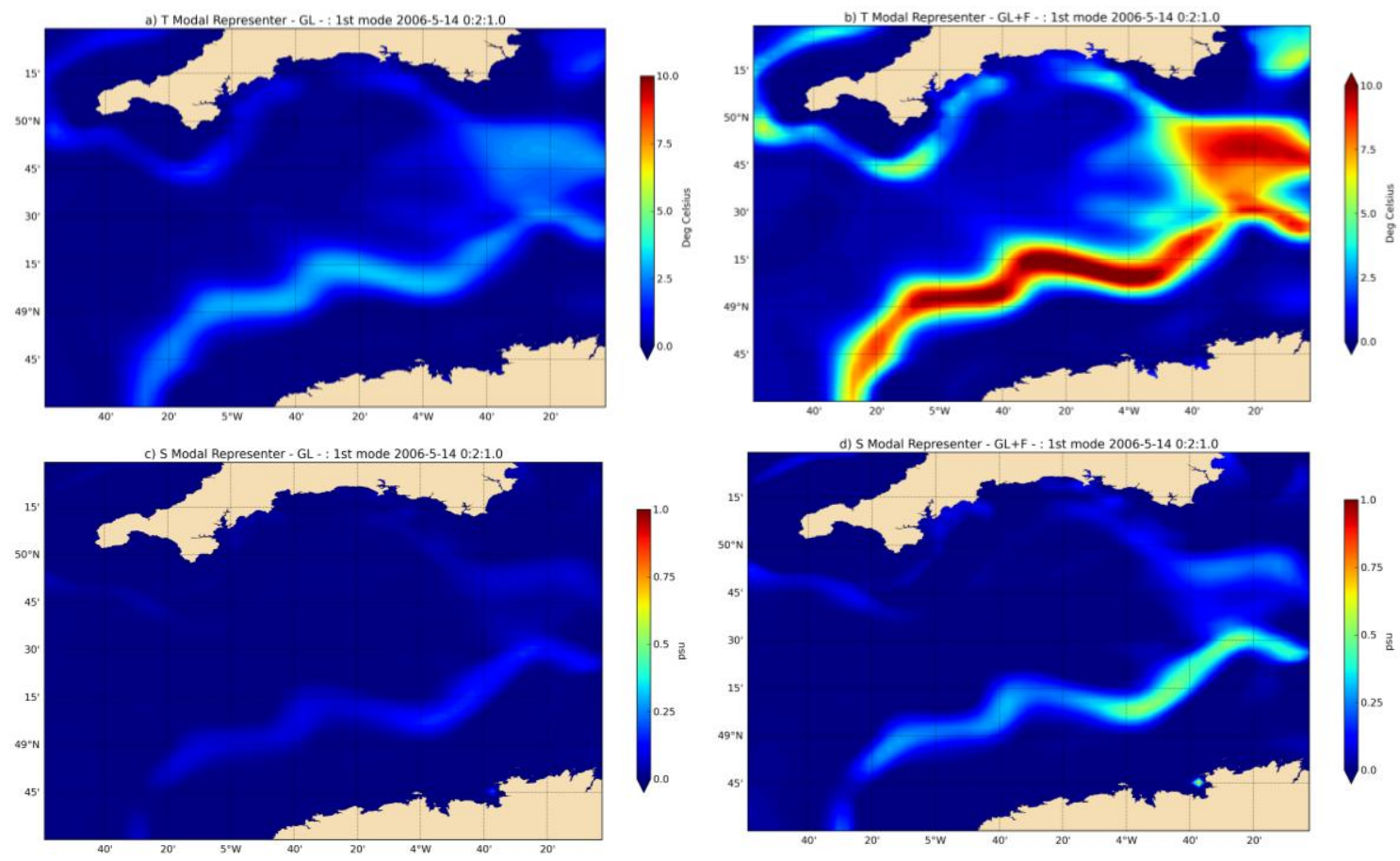

Figure 10: First modal representer of Temperature $(a, b)$ and Salinity $(c, d)$ in surface layer for the GL (glider only) network (a, c) and the glider+FerryBox network (b, d) for the 14th May 2006.

\subsection{Concluding remarks in the WEC region}

The WEC region, under the influence of the strong tide dynamics and proposing an existing FerryBox line, provides an ideal test case to assess the potential added value of using autonomous gliders below a FerryBox regular line.

Results clearly show the efficiency of the only-FerryBox line to monitor the dynamics in the region and by extension to constrain model errors. As a complementary sensor, the glider does not bring significant enhancement to the FerryBox efficiency. Indeed, the glider only samples a limited number of degrees of freedom of the observed system.

\section{Conclusions and perspectives}

Through two distinct experiments, in the vicinity of the Loire River plume and in the western English Channel, it has been demonstrated that the use of gliders as an operational system to monitor coastal hydrology is not always a universal answer. Indeed, following the hydrodynamical context (e.g. stratification conditions, tidal regimes) and the existing observing platforms, the glider does not systematically improve the efficiency of the existing observing networks. In the Loire region, the glider is clearly improving the monitoring of the river plume while in the WEC region, the glider does not significantly complement the observations collected by the FerryBox line. These contrasted conclusions can be explained by the characteristics of the different regions and the associated observing platforms and in practice this warrants the inclusion of modal representers in the ArM analysis in order to identify the detected processes.

The application of the ArM method in a multiparameter (temperature and salinity) dimension, and for various glider endurance lines in the Loire region, gives insights in the best sampling strategy for glider deployment in the region. The along-shore and meridional glider sections which were explored here (GL4/GL5) show a slightly more efficient sampling of model 
uncertainties in the area than the cross-shore initial design. On the opposite, the cross-shore transects efficiency is not related to the glider direction.

All these results have to be considered in the scope of the implemented numerical experiments and in particular in the scope of the physical assumptions initially made in the generation of the prior errors. On the other hand, the present study has been performed for a given period and with a fixed model configuration, including specific spatial and temporal resolutions. These settings were adapted to the period and physics at hand, and cannot be considered general. Nevertheless, we believe in the general approach followed here, according to which, when designing observational networks in a given area, one cannot ignore the sustainable modelling efforts which are conducted there; in that framework, we believe that the paradigm expressed at the beginning of Section 2 about what a "good" array is, based on how much information it will add on top of a prior model estimate, is of effective value. Similarly, the approach of opening degrees of freedom of prior (model) error through stochastic modelling is both effective (in the context of the ArM analysis) and physically insightful, as it prompts us to elucidate which physical error sources in the local, sustained modelling system are most prejudicial to the quality of estimates. In that sense, more physics-related degrees of freedom of error could be considered. But this is an iterative process: as new data will come in, new prior errors will be revealed, and the strategy can be adapted as a consequence.

Overall, with the increasing complexity of the observation networks to design (pluridisciplinary parameters - biogeochemistry, turbidity; new platforms - HF radar), the ArM method appears as a valuable numerical solution to guide the optimization of the future networks and the related decisions.

\section{Acknowledgements}

This study has been undertaken in the frame and with the financial support of the PREVIMER project, the JERICO (WP9) project from the European Union Seventh Framework Programme (FP7/2007-2013) under grant agreement no. 262584, and the FP7 SANGOMA project (FP7-SPACE-2011-283580). We would like to thank Catherine Heyraud, Stéphane Raynaud, Philippe Craneguy (Actimar service company) and Franck Dumas (Ifremer) for the development of ensemble simulations using the MARS3D model. We warmly thank Matthieu Le Hénaff for fruitful discussions. We also thank the Station Biologique de Roscoff for collecting and providing FerryBox data (Brittany Ferries, INSU, Ifremer) from MV Armorique. We are grateful to anonymous referee for constructive comments on this manuscript.

\section{References}

Charney, J., Halem, M., Jastrow, R., 1969. Use of incomplete historical data to infer the present state of the atmosphere. Journal of the Atmospheric Sciences 26 (5), 1160-1163.

Charria, G., M. Repecaud, L. Quemener, A. Ménesguen, P. Rimmelin-Maury, S. L'Helguen, L. Beaumont, A. Jolivet, P. Morin, E. Macé, P. Lazure, R. Le Gendre, F. Jacqueline, R. Verney, L. Marié, P. Jegou, S. Le Reste, X. André, V. Dutreuil, J.-P. Regnault, H. Jestin, H. Lintanf, P. Pichavant, M. Retho, J.-A. Allenou, J.-Y. Stanisière, A. Bonnat, L. Nonnotte, W. Duros, S. Tarot, T. Carval, P. Le Hir, F. Dumas, F. Vandermeirsch, F. Lecornu,PREVIMER: 
A contribution to in situ coastal observing systems, Quarterly Newsletter MERCATOROcean, 49, April 2014.

Costoya, X., deCastro, M., Gomez-Gesteira, M., Santos, F. (2015), Changes in Sea Surface Temperature Seasonality in the Bay of Biscay over the last decades (1982-2014), Journal of Marine Systems, doi: 10.1016/j.jmarsys.2015.06.002.

deCastro, M., M. Gómez-Gesteira, I. Alvarez, J.L.G. Gesteira, 2009. Present warming within the context of cooling-warming cycles observed since 1854 in the Bay of Biscay, Continental Shelf Research, Volume 29, Issue 8, Pages 1053-1059, ISSN 0278-4343, http://dx.doi.org/10.1016/j.csr.2008.11.016.

Duhaut T, Honnorat M, Debreu L (2008) Dé• veloppements numériques pour le modèle MARS. Rapport PREVIMER contrat N06/2 210290.

Frolov, S., Baptista, A., Wilkin, M., 2008. Optimizing fixed observational assets in a coastal observatory. Continental Shelf Research 28, 2644-2658.

Fu, W, J. L. Hoyer, and J. She, 2011. Assessment of the three dimensional temperature and salinity observational networks in the Baltic Sea and North Sea, Ocean Sci., 7, 75-90, doi:10.5194/os-7-75-2011.

Gómez-Gesteira, M., M. deCastro, F. Santos, I. Álvarez, X. Costoya, Changes in ENACW observed in the Bay of Biscay over the period 1975-2010, Continental Shelf Research, Volume 65, 15 August 2013, Pages 73-80, ISSN 0278-4343, http://dx.doi.org/10.1016/j.csr.2013.06.014.

Gonzalez-Pola, C., Lavın, A., and Vargas-yanez, M. (2005). Intense warming and salinity modification of intermediate water masses in the southeastern corner of the Bay of Biscay for the period 1992 - 2003. Journal of Geophysical Research: Oceans, 110(1), 1-14. doi:10.1029/2004JC002367.

Hackert, E.C., Miller, R.N., Busalacchi, A.J., 1998. An optimized design for a moored instrument array in the tropical Atlantic ocean. Journal of Geophysical Research 103, 74917509 .

Hill, A. E., Brown, J., Fernand, L., Holt, J., Horsburgh, K. J., Proctor, R., Raine, R., and Turrell, W. R. (2008). Thermohaline circulation of shallow tidal seas. Geophysical Research Letters, 35(11), 5-9. doi:10.1029/2008GL033459.

Kelly-gerreyn, B. A., Hydes, D. J., Jegou, A. M., Lazure, P., Fernand, L. J., Puillat, I., \& Garcia-soto, C. (2006). Low salinity intrusions in the western English Channel. Continental Shelf Research, 26, 1241-1257. doi:10.1016/j.csr.2006.03.007.

Kourafalou V.H., P. De Mey, M. Le Hénaff, G. Charria, C.A. Edwards, R. He, M. Herzfeld, A. Pasqual, E.V. Stanev, J. Tintoré, N. Usui, A.J. Van Der Westhuysen, J. Wilkin and X. Zhu, 2015. Coastal Ocean Forecasting: system integration and validation. Journal of Operational Oceanography, doi:10.1080/1755876X.2015.1022336. 
Kuo, Y.H., Zou, X., Huang, W., 1998. The impact of global positioning system data on the prediction of an extratropical cyclone: an Observing System Simulation Experiment. Dynamics of Atmospheres and Oceans 27 (1), 439-470.

Lamouroux, J., G. Charria, P. De Mey, S. Raynaud, C. Heyraud, P. Craneguy, F. Dumas, M. Le Hénaff (2016), Assessment of RECOPESCA network contribution for the monitoring of 3D coastal model errors in the Bay of Biscay and the English Channel, Ocean Dynamics, 66(4), doi:10.1007/s10236-016-0938-y.

Lazure P, Dumas F (2008) An external-internal mode coupling for a 3D hydrodynamical model for applications at regional scales (MARS). Advances in Water Resources. 31(2):233250. http://dx.doi.org/10.1016/j.advwatres.2007.06.010.

Lazure, P., and Jegou, A. (1998). 3D modelling of seasonal evolution of Loire and Gironde plumes on Biscay Bay continental shelf. Oceanologica Acta, 21(2), 165-177. doi:10.1016/S0399-1784(98)80006-6.

Le Cann, B. (1990). Barotropic tidal dynamics of the Bay of Biscay shelf: observations, numerical modelling and physical interpretation. Continental Shelf Research, 10(8), 723758. doi:10.1016/0278-4343(90)90008-A

Le Hénaff, M., P. De Mey, and P. Marsaleix, 2009. Assessment of observational networks with the representer matrix spectra method - application to a $3 \mathrm{~d}$ coastal model of the Bay of Biscay. Ocean Dynamics. doi:10.1007/s10236-008-0144-7.

Lin, P., R. Ji, C. S. Davis, and D. J. McGillicuddy Jr, 2010. Optimizing plankton survey strategies using Observing System Simulation Experiments, Journal of Marine Systems, 82, 187-194, doi:10.1016/j.jmarsys.2010.05.005.

Marrec, P., T. Cariou, E. Collin, A. Durand, M. Latimier, E. Macé, P. Morin, S. Raimund, M. Vernet, Y. Bozec, 2013. Seasonal and latitudinal variability of the CO2 system in the western English Channel based on Voluntary Observing Ship (VOS) measurements, Marine Chemistry, Volume 155, Pages 29-41, ISSN 0304-4203, http://dx.doi.org/10.1016/j.marchem.2013.05.014.

Marrec, P., T. Cariou, M. Latimier, E. Macé, P. Morin, M. Vernet, Y. Bozec, 2014. Spatiotemporal dynamics of biogeochemical processes and air-sea $\mathrm{CO} 2$ fluxes in the Western English Channel based on two years of FerryBox deployment, Journal of Marine Systems, Volume 140, Part A, Pages 26-38, ISSN 0924-7963, http://dx.doi.org/10.1016/j.jmarsys.2014.05.010.

Michel, S., Treguier, A.M., Vandermeirsch, F., 2009a. Temperature variability in the Bay of Biscay during the past 40 years, from an in situ analysis and a 3D global simulation. Cont. Shelf Res. 29, 1070-1087. 
Michel, S., Vandermeirsch, F., Lorance, P., 2009b. Evolution of upper layer temperature in the Bay of Biscay during the last 40 years. Aquat. Living Resour. 22, 447-461, doi:10.1051/alr/29009054.

Pingree, R. D., Sinha, B., abd Griffiths, C. R. (1999). Seasonality of the European slope current (Goban Spur) and ocean margin exchange. Continental Shelf Research, 19(7), 929975. doi:10.1016/S0278-4343(98)00116-2.

Puillat, I., Lazure, P., Jegou, A. M., Lampert, L., \& Miller, P. I. (2004). Hydrographical variability on the French continental shelf in the Bay of Biscay, during the 1990s. Continental Shelf Research, 24, 1143-1163. doi:10.1016/j.csr.2004.02.008.

Salomon, J.C., Breton, M., 1991, Long-term tidal currents in the Channel. Oceanologica Acta $11,47-53$

Salomon, J.C., Breton, M., 1993. An atlas of long-term currents in the Channel. Oceanologica Acta 16, 439-448.

Schulz-Stellenfleth, J., and Stanev, E. V., 2010. Statistical assessment of ocean observing networks - A study of water level measurements in the German Bight. Ocean Modelling, 33(3-4), 270-282. doi:10.1016/j.ocemod.2010.03.001. 